\title{
The Impact of the Institution of Religion on Organizational Decision Making: The Case of Leveraged Buyouts
}

Aviad Pe'er A*

Sauder School of Business, University of British Columbia, Canada

\begin{abstract}
This paper sheds light on the role of religion as a separated institutional logic on firm behavior and performance, particularly in the context of corporate development strategies and decision making. We argue that religiosity in a firm's environment influences decision making of organizations when initiating and evaluating corporate development strategies and hence leading to uneven distribution of economic activity. We focus on leveraged buyouts (LBOs) an important strategic initiative associated with high levels of perceived risk from increased financial leverage, a drastic change in governance structure, and potential conflicts between stakeholders. We contend that local religiosity reduces the likelihood of LBO transactions that nonetheless creates a favorable selection process resulting in a lower rate of LBO bankruptcies. We find results supporting our predictions in a unique sample of 4,633 US buyouts in 1980-2003.
\end{abstract}

Keywords: Religion; Organizational decision making; Institutional context; Spatial distribution; Private equity; Corporate development strategies

\section{Introduction}

Numerous studies grounded in institutional theory have documented the influence of institutional contexts on firm behavior and performance [1]. Prominent examples include studies of multinational enterprise (MNE) strategies [2-9] corporate responses to environmental demands [10], the costs of adopting environmental management systems [11], the promotion of corporate sustainable development [12], firm disclosure strategies [13], and the process of strategic decision making in general [14].

While most of these studies have considered a wide range of institutions in their analysis, the role of religion (one of the five core institutions), as a separated institution and a distinguished source of an institutional logic $[15,16]$, has received, to the best of our knowledge, no attention by organizational scholars, and only meager attention by institutional researchers themselves. Religiosity is the extent to which a system of thoughts, values and feelings is shared by a group and influences members' code of behavior by which individuals may judge the personal and social consequences of their actions [16]. Therefore, religiosity is one aspect of institutional context that seems intuitively important as a determinant of firm conduct and performance Smith [17]. In fact, the role of religion has been part of economic thought since weber $[18,19]$, who conceptualized it as a rational action by which individuals enhanced the value of their human capital, and Weber, who credited capitalism's success to the Protestant work ethic. More recently, a stream of literature at the micro-economic level has linked religion to a large range of individual decisions. A second and newer stream of literature has focused on religion and macro-economic growth. For example Barro [20], found that macroeconomic development has a negative correlation with church attendance. Similarly Haveman [21], documented an association between religious beliefs and economic attitudes conducive to higher per capita income and growth across countries.

Although these streams of research provide valuable insights about the influence of religion on economic behavior in general, a systematic theory of how religion influences firm behavior and performance has yet to be developed, particularly in the context of corporate development strategies and decision making. In fact, the influence of religion on corporate activity is often explicitly ignored, and the role of religion as a key institutional factor in the environment is habitually underplayed.

Our study bridges this gap in organization literature by considering the roles religiosity plays in organizational values, preferences, and sense of duty in decision making. Building on research on institutional logics and following the work of Boltanski and Thevenot [14,15,21-24], on "regimes of justification" and their impacts on decision making, we argue that the extent of local religious adherence (hereinafter religiosity) influences firms' decisions when initiating and evaluating corporate development strategies. Local religiosity influences organizational decisions in terms of risk, the social outcomes considered, as well as what is perceived appropriate and expected from the organization in a specific context. For example, recent reports show that faith-based mutual funds incorporate ethical values in selecting securities, excluding companies that violate the tenets of a given religion or religious denomination (WSJ) [25]. Investors find meaning by "putting their money where their faith is," making morally responsible mutual funds one of the fastest-growing subsets of socially responsible investing. Religiosity influences organizations by establishing the context in which they develop or endorse new corporate strategic decisions. As an initial demonstration of the significance of organizations' religious environment, we develop and test the extent to which it influences organizational decision making with respect to engagement in leverage buyout transactions.

We focus on leveraged buyouts investments (hereinafter referred to as buyouts or LBOs) as an excellent example of a major corporate development strategy associated with a drastic change in governance structure, and potential conflicts of interest with a firm's stakeholders. Buyouts are a form of economic takeover that has become increasingly popular over the last several decades. The amount of capital committed

*Corresponding author: Aviad Pe'er A, Sauder School of Business, University of British Columbia, Canada, Tel: 9733531703; E-mail: apeer@business.rutgers.edu

Recieved November 16, 2015; Accepted January 20, 2016; Published January 30, 2016

Citation: Pe'er AA (2016) The Impact of the Institution of Religion on Organizational Decision Making: The Case of Leveraged Buyouts. J Entrepren Organiz Manag 5: 163. doi:10.4172/2169-026X.1000163

Copyright: (c) 2016 Pe'er AA. This is an open-access article distributed under the terms of the Creative Commons Attribution License, which permits unrestricted use, distribution, and reproduction in any medium, provided the original author and source are credited. 
to US private equity funds grew from $\$ 0.2$ billion in 1980 to over $\$ 300$ billion in 2007, with much of the growth occurring after 2000 Lerner and strom $[26,27]$. By the peak of the last economic cycle, in 2007, LBOs had become responsible for almost half of $\mathrm{M}$ and $\mathrm{A}$ activity worldwide. At the beginning of 2011, LBO leader Kohlberg Kravis Roberts and Co. (KKR) owned stakes in over 60 firms for a total of more than \$ 205 billion in sales and over 900,000 employees. LBOs are fundamentally a risky endeavor from organizational and social perspectives, for the firm's stakeholders, and for overall firm survival Peer organizations' $[28,29]$, decision making, leading to a lower level of buyout activity at a higher level of local religiosity. Consequently, we hypothesize that high levels of religiosity in a firm's environment will translate into lower levels of bankruptcies among buyouts, because firms are more likely to pursue an LBO strategy when they are particularly confident about acceptance by stakeholders in the community and chances of success (and hence lower transaction costs).

We test our predictions with a unique, deal-level dataset of 4,633 buyout investments between 1980 and 2003 in the United States, the world's largest and oldest buyout market. We use religiosity at the county level to proxy for religiosity in firms' institutional environments. Our results indicate that a high level of religiosity in a county was associated with a smaller volume of LBOs in that county, and that buyout transactions in more-religious counties were less likely to enter bankruptcy.

\section{Theory and Hypotheses}

\section{Institutional influences on organizational decision making}

Institutional theory posits that the institutional environment in which firms operate influences their tendency to pursue value-creating strategies [30-32]. Scott conceptualized the institutional environment as the "cognitive, normative, and regulatory structure and activities that provide stability and meaning to social behavior" [1], Scott emphasized the role of institutions in defining the "rules of the game" based on formal and informal elements that shape political, economic and social relationships. Formal elements include regulations; informal factors include codes of conduct and norms [2]. Institutions play an important role for firms in market economies by ensuring that market mechanisms function, allowing firms and individuals to engage in transactions without incurring undue costs or risks [3].

The institutional context has political and social elements. Political institutions include governments and the constraints they impose on key economic actors. They govern the rules and enforcement of tax rates, tariffs, investment incentives regulations Laportal [33,34], restrictions on foreign ownership [35], government protection [36], labor relations, minimum wage [37], and environmental regulations [38]. Social institutions, meanwhile, are embodied in differences in work ethic (Weber attitudes toward work $[33,39]$ beliefs concerning the basis of productivity [40], and productive capacity, and are the normative and cognitive bases for social exchange [41].

Together, political and social institutions directly influence the costs of engaging in business activity in a given environment and the returns that firms can achieve on their investments. Along with technology, the institutional environment determines transaction costs and transformation costs of production, and thus the profitability of engaging in business activity [42]. In the words of Ingram and Silverman, "Institutions directly determine what arrows a firm has in its quiver as it struggles to formulate and implement strategy and to create competitive advantage."
The institutional environment impacts firm behavior and performance. According to the institutional perspective, organizational choice is limited by a variety of external pressures. Environments are collective and interconnected $[43,44]$ and organizations must be responsive to external demands and expectations in order to survive. Conformity and congruency with the institutional environment and adherence to external rules are essential for an organization to obtain legitimacy and acceptance by its external environment norms and values. Obtaining and sustaining acceptance by the environment can be so powerful that choices that may serve the organization's selfinterest and economic viability (e.g., enhance efficiency, control, and profitability) are suppressed and dominated by (at times contradictory) choices to conform, accept, adhere and fit the institutional norms, rules, and values [45].

More recently, Friedland and Alford's [14], seminal essay, together with empirical work by Haveman [46], created the institutional logic approach - a new approach to institutional analysis which posited institutional logics as defining the content and meaning of institutions. They focus on the effects of differentiated institutional logics on individuals and organizations in a larger variety of contexts, including markets, industries, and populations of organizational forms. They argue that religion does not only defines the rules and puts a pressure on organization to conform (in order to achieve legitimacy), but it has a central logic that guides its organizing principles and co-shapes rational behavior by providing social actors with vocabularies of motive and a sense identity. Friedland and Alford [14], posit religion as one of the five core institutions of western society (others are: the capitalist market, the bureaucratic state, families, and democracy). Accordingly, religion provides a central logic that constrains both the means and ends of individual and organizational behavior at the same time that it provides opportunities for agency and change. While there is vast evidence to institutional logic in variety of empirical contexts (such as thrifts higher education publishing $[47,48]$, health care organizations mutual funds [49]. French cuisine, and equity markets the unique impacts of religion on organizational values, preferences, and sense of duty in decision making has been mostly neglected. In light of the rising salience of religions in the world system, the question of what implications it bears for the notable presence of market logics is particularly relevant. We set to address this issue within the context of organizational decision making.

\section{The influence of religion on organizational decision making}

Religiosity is one aspect of the institutional context that seems intuitively important as a determinant of corporate decision making and subsequently firm conduct and performance. Following the extant literature on religion, we consider religiosity as the extent to which an individual, and in aggregation a community, ascribes to the beliefs, experiences, and rituals of a religion [16]. The role of religion has been part of economic thought, who conceptualized it as a rational action by which individuals enhanced the value of their human capital. As postulated, the links between religiosity and economics have the potential "...to enhance economics at several levels: generating information about a neglected 'nonmarket' behavior; showing how economic models can be modified to address questions about belief, norms and values; and exploring how religion (and by extension, morals and culture) affect economic attitudes and activities of individuals, groups, and societies."

These links have been recognized at both the macro and micro levels. Nevertheless, and perhaps surprisingly, the literature has only rarely considered how religiosity in the institutional context might 
impact organizational decision making, firm conduct, and performance.

One well-established stream of economics literature has examined religion and economic growth at the macro level. Weber [18], proposed that the Protestant work ethic was a fundamental driver of economic development in capitalist societies. More recently, scholars have used religion to explain cross-sectional variation at the country level in creditor rights by stulz [49], government quality, and economic growth. While insightful, country level data is prone to omitted variables problems because it is difficult to separate interrelated forces such as the legal environment, religion, government, culture, and economic structures. This can be addressed somewhat by exploiting the substantial heterogeneity across US states. Gelman [50], for example, used statelevel data to explain the relationships between political polarization, income inequality, social ideology, and religious attendance. Our study disaggregates the data even further by using county-level data.

There is also a substantial body of research on the role of religiosity at the micro level. A number of studies document a link between religiosity and risk aversion at the individual level. For example, reported a negative correlation between religiosity and individual appetites for risk and danger. Similarly, Osoba [51], found that riskavoidance behavior (operationalized by various individual decisions such as financial conservatism, levels of medical and car insurance coverage, smoking habits, and seat belt fastening) is positively correlated with church attendance, while found that Las Vegas residents who selfreported placing a higher importance on religious practice (by attending services regularly) also gambled less frequently and for lower amounts than those who attended services sporadically. Halek and Eisenhauer [52], showed a similar positive correlation between religion and risk aversion using survey data on insurance purchases. Finally, Dehejia et al. [53], found that individuals with a regular religious practice had lessvolatile income streams.

Our focus in this paper is the relationship between religiosity and corporate decision making, and by extension with firm conduct and performance. In order to explain this relationship, we need to understand how the extent of religiosity influences organizational decision making with respect to the regimes of justification. While most of the empirical literature has studied religiosity at the individual and national levels, our theoretical development and data exploitation capture the extent of religiosity in the (target) firms' environment. Several premises underlying our study; First, embeddedness in a religious context should impact one's values, norms, and actions regardless of one's own level of religiosity. Consistent with this, recent work by van Hoorn and Maseland [54-56], tested the relationship between Protestantism (the dominant religious denomination in the US) and work attitude by examining the effect of unemployment on individuals' subjective well-being. They found that the well-being of Protestants is influenced more by being unemployed (relative to having a job) than is the wellbeing of people from other denominations. Importantly, and key to our argument regarding the influence of local religiosity on organizational decision making, they found that "it is not so much Protestant individuals who are hurt more by being unemployed as it is individuals (both Protestants and non-Protestants) living in Protestant societies" (10). Second, a large body of literature on social identity theory suggests that individuals opt to work in an area characterized by local beliefs and culture with which they feel comfortable, and are influenced by social norms through interactions that further reinforce their experiences, preferences, and behaviors . Consistent with this expectation, financial economists have identified a geographic bias toward home. For example, shareholders who reside near a firm's headquarters tend to have a relatively larger share of ownership compared to shareholders who live far away. Third, executives tend to reside near their firm's headquarters. For instance, Murphy and Shleifer [57], demonstrated that social interactions affect portfolio decisions. This suggests that executives and local shareholders' beliefs and values will be influenced by their personal social network consisting of families, friends, and colleagues, the media to which they are exposed, and the local civic institutions with which they associate. Consistent with this general view, recent literature in economics empirically examines the impact of local religious beliefs on mutual funds' investment decisions, tax avoidance, option grants, lower variance in return on assets (ROA), or in equity returns Hilary and Hui [58].

Local religiosity is expected to shape organizational preferences and expectations. The extent of religiosity in the local environment influences corporate culture, norms, and values to correspond to those of the community. Religion embodies shared values and gives rise to normative expectations and emphasizes inspirational- over marketjustifications in decision making. These influences can manifest themselves directly in observed practices or preferences, as well as indirectly by what information is considered in the decision process. The extent of religiosity also impacts organizations' reliance on the logic of what is expected from the organization in the fulfillment of its roles and identities that are socially defined. In line with institutional theories, much of an organization's identity is derived from its position in a social context. Organizations adopt and internalize the norms, values, and attributes of their environment. March and Olsen [59], argued that "Actors following internalized prescriptions of what is socially defined as normal, true, right, or good, without, or in spite of, calculation of consequences and expected utility" (690). Thus, an expectation regarding what is the "right thing to do" is likely to induce organizations to take lower risks to maintain their social position if their decisions are viewed as highly risky for relevant stakeholders than would be prescribed by rational utility maximization only.

Next, we describe the context of buyout as a particular strategic initiative that we use for our empirical analyses and the impact of religion on buyout activity and likelihood of failure.

\section{Buyout value generation}

A buyout can be defined as "the purchase of a controlling stake in a company (or a division) from its owners for a limited time, usually financed through a combination of equity and debt and with strong involvement of specialized financial investment companies". Most buyouts are sponsored by private equity funds, which exit their investments after a limited horizon. Analyzing the Capital IQ database between 1970 and 2007, found a median holding period of around six years, with $12 \%$ of deals completed (exited) within 24 months of the acquisition date. Indeed, "[T]he ability to achieve a successful exit before the end of the fund life is considered to be crucial for the financial performance of a private equity investor". The most common routes of "successful" exit are selling the company to a strategic buyer, selling it to another private equity fund, or holding an initial public offering. "Unsuccessful" exits are write-offs or bankruptcies.

Decision-making and screening strategies of investment funds have been studied extensively (e.g., Barnett and Salomon, 2006 for screening criteria and performance of socially responsible investments by mutual funds; Buyouts are different from other investment funds in important ways that make them particularly suitable setting for examining our theory. First, buyouts represent a major change in corporate strategy. They are perceived as risky from organizational and social perspectives, 
for the firm's stakeholders, and for overall firm survival. Second, they are archetypes of "unrelated" acquisitions, as buyout firms tend to manage companies independently from one another rather than seeking to maximize performance of a portfolio of firms. Third, buyouts do not apply selection criteria other than a clear attempt to maximize the market value of the acquired target (beyond the purchase price).

With freedom from the scrutiny of being a public company or a captive division of a larger parent, and with limited contractual lifetimes, buyouts want to build value (quickly) by improving profitability, pursuing growth opportunities, selling or shutting down less efficient units, activities, or projects, de-unionizing, and improving corporate governance to better align management incentives with shareholder incentives. Buyouts often substantially change the way a target firm's operations are organized and managed, with the goal of reducing costs and improving margins [60]. After an acquisition, the management immediately starts to tighten control on corporate spending) and initiates a series of cost reduction programs.

Buyout funds use extensive leverage in acquisitions. In addition to the severe default risk associated with the need to serve a large debt position, debt payments can force management to improve performance and operating efficiency. This "discipline of debt" leads management to focus on certain initiatives such as divesting non-core businesses, downsizing, or cost cutting. In this manner, debt serves not just as a financing technique, but also as a tool to force changes in managerial behavior. Buyout funds typically invest alongside (existing or recruited) management, encouraging (if not requiring) top executives to commit a significant portion of their personal net wealth to the deal. As a general rule, buyout firms will own $70-90 \%$ of the common equity of the target firm, with the remainder held by management and former shareholders. By requiring the management team to invest in the acquisition, the private equity firm guarantees that management's incentives will be aligned with its own. The impact of religion on buyout activity and likelihood of failure.

Buyouts are a particularly clean example of a strategic initiative that is associated with high levels of perceived risk. The use of increased financial leverage, a drastic change in governance structure, and potential conflicts of interest between firm stakeholders faced with restructuring-oriented, value-creating strategies are fundamentally risky endeavors.

Interestingly, very few buyouts happen as so-called "hostile takeovers"; most are initiated by a firm's management team. Managers often trigger buyout transactions while trying to exploit value-creating opportunities personally (with the buyout fund). Because these opportunities may not build value for existing shareholders, buyouts may be perceived as "corporate raiders". Furthermore, anti-takeover legislation, which gives management the right to veto a takeover by making it more difficult to finance, is more likely to be adopted early in states with high percentages of religious adherents.

We contend that the extent of local religiosity influences the preferences incorporated into decisions in terms of risk and the social outcomes being considered. Thus, when evaluating collaboration with buyout funds, organizations in more religious communities are more likely to account for anticipated moves under the buyout ownership that will be in conflict with their risk preferences and social values.

From an institutional perspective, the extent of religiosity in the environment influences organizational norms and values to correspond to those of the community. Thus, we argue that when organizations in more religious communities are embedded in an institutional environment with stronger values towards stability, more certain (i.e., low variance) outcomes, and long-term perspectives, they are also likely to internalize these values and preferences, and therefore less likely to engage in buyout transactions. Moreover, as the valuegenerating moves associated with buyouts are likely to be in conflict with existing shareholders and stakeholders, organizations in more religious communities are less likely to engage in those transactions since they place high value on being pro-social and on being perceived as aligned with the broader community well-being. Hence, they would also be less likely to initiate or agree to a buyout and only do so if they feel particularly confident about its chances of success.

Organizations in more religious communities are likely to act in accordance to and conform to what is expected from them by their communities. Religiosity promotes intra-group trust among adherents and hence impacts organizations' sense of obligation to and cohesion with the community. Accordingly, they rely on what is perceived appropriate and expected from them by members of a community. Thus, when considering collaboration with buyout funds, organizations in more religious communities will more likely to engage in more rigorous screening such as accounting for anticipated moves under the new ownership that will be in conflict with their social roles such as shutting down facilities, laying off employees, deunionization, preferring lowcost suppliers over local suppliers, and outsourcing.

Based on the theoretical development above, we can make specific predications about the role of religion as a determinant of buyout activity and success. We argue that religiosity spills-over to corporate culture, which in turn affects organization decision making and interactions with buyouts. In an institutional context characterized by high levels of religiosity, where risk aversion and social preferences would dispose organizations against riskier initiatives, and where employing an LBO strategy may conflict with duties and obligations that organizations have towards stakeholders, we anticipate lower levels of buyout activity. We would further expect that high levels of religiosity in a firm's institutional environment will translate into lower levels of bankruptcies among buyouts, because organizations are more likely to pursue an LBO strategy when they are particularly confident about their acceptance by stakeholders in the community, hence reducing transaction costs of implementing buyout strategies, and increasing chances of success. Stated differently, to maintain their social roles, their commitment and trust to local stakeholders, as well as their risk-averse and social preferences, organizations in more religious communities would be more likely to initiate or agree to a buyout while applying higher success thresholds and conservative assessments to their decisions. Thus, corporate decision making in more religious communities will create lower transaction costs associated with the implementation of restructuring-oriented buyout value-generating strategies than will corporate decision making in less religious communities.

In line with this reasoning, we hypothesize that, ceteris paribus, the likelihood of firms located in more-religious communities becoming targets for buyout acquisitions is lower than for companies located in less-religious communities. At the same time, all else being equal, we hypothesize that individual buyouts will be less likely to fail when they are located in more religious communities.

Hypothesis 1: The level of activity of leveraged buyouts will be lower at higher levels of religious adherence in the community.

Hypothesis 2: The average performance of buyouts improves with the level of religious adherence in the community where the target firm is headquartered. 


\section{Data and Research Design}

We focus our study on the United States, the world's largest and oldest buyout market. The US has a higher level of religious practice than other countries with similar levels of socioeconomic development. For example, showed that church membership rates in the US steadily increased during the past two centuries; the proportion of people attending church weekly is now four times higher in the US than in Scandinavian countries. According to the American Religious Identification Survey (ARIS) of 2008 the US is overwhelmingly Christian (primarily Protestant), other religions (including Judaism, Buddhism, Islam, and Hinduism) collectively make up about $4 \%$ of the adult population. An additional advantage of focusing on one country is that we obtain a more homogeneous sample in terms of financial and economic development, legal structure, public infrastructure, and so forth.

Basic descriptive statistics about the level of private equity activity and the degree of religiosity suggest substantial variability across counties in the US; hence, when available, we collected our data at the county level. Following the previous literature we define a firm's location as the location (county) of its operation headquarters. As noted this approach seems "reasonable given that corporate headquarters are close to corporate core business activities."

\section{Data sources}

To conduct our analyses, we matched three data categories: private equity funds, religiosity, and various controls for alternative determinants of private equity activity and the likelihood of failure of individual transactions.

Private equity funds: We obtained the corresponding information on private equity funds raised in 1980-2003 from Thomson Venture Economics (TVE). TVE collects detailed information on a fund's underlying investments in its "investment" database, the most comprehensive source of information about both US and European private equity funds. This database, Venture Xpert, which has been widely used in academic research, contains information on private equity investments in 29,739 companies.

The investments data include information about the target company (location, industry group, age), the investment (time of investment, stage, group of co-investors (syndicate), equity amount provided by each fund, exit date, and exit mode for liquidated investments), and the fund (investment focus, vintage year). Venture Xpert codifies industry descriptions for the target companies into ten categories: communications and media, computer related, electronics, biotechnology and pharmacology, medical/health related, energy related, consumer related, industrial products, other services, and manufacturing/other.

Thomson Venture Economics was able to obtain its data because it has a decades-long relationship with the GP and LP community, which otherwise keeps information about private equity investments confidential. Complete coverage of all investments by all funds remains difficult to achieve. Kaplan, studied the accuracy of Venture Xpert and found that discrepancies arose from the treatment of milestone rounds; many are missing in the dataset. Evaluated the quality of Venture Economics databases and found that the reported deals covered about $90 \%$ of the total in terms of value, and that the number of rounds was overstated. Their analysis shows that Thomson Venture Economics data do not suffer from any significant biases that would impair our analysis.

Religiosity: We used the "Churches and Church Membership" files published by the Association of Religion Data Archive (ARDA). This dataset, collected by the Department of Sociology, Pennsylvania State University, provides the most rigorous and longitudinal information on religiosity at the country level. Appendix A presents a large discrepancy in religiosity across states: from $35 \%$ in Oregon to $85 \%$ in Louisiana. The variance in religiosity across counties is even larger from $3 \%$ in Alpine, CA ( 1 church, 45 religious people in a population of 1,113 as of 2000 ) to $99.67 \%$ Swisher, TX (27 churches, 8,106 religious people in a population of 8,133 as of 2000). On the other hand, the majority of buyout funds are located in four low religiosity metropolitan areas (New York, Chicago, Boston, and San Francisco). Given their business model, incentives and competition in the private equity industry, they are likely to use market value set when evaluating a potential target. Hence, and consistent with our theoretical development, we focus on the social environment in the location of the target firm.

Controls: Regional Accounts from the US Bureau of Economic Analysis provided the information on population, income growth, population and population density. The Economic Research Service of the US Department of Agriculture provided information about college degrees. Finally, the Local Area Unemployment Statistics (LAUS) file from the US Bureau of Labor Statistics yielded the labor force data for each county.

To examine our theoretical predictions, we formulated two distinct models that explain the impacts of religiosity on (1) the level of buyout activity, and (2) the likelihood of failure of individual transactions.

\section{Sample selection and dependent variables}

We focus on the subset of the Thomson Venture Economics databases that contain all 14,825 investments classified as "buyouts" for all private equity funds that participate in any of these investments. Many acquisitions are done as syndicates ("club deals"), or include more than one recorded round of investment. If we remove those multiple counts, the remaining sample contains 4,633 buyout investments in distinct target companies (i.e., acquired companies) by 1,300 different private equity firms. We provide robust standard errors adjusted for clustering on PE firm and fund, and include a "club deal" dummy .

The dependent variable in our examination of $\mathrm{H} 1$, the local level of buyout activity, is a count of all buyouts in a given calendar year of companies located in any of the 3,009 counties. Our sample covers 72,216 county-year observations.

For $\mathrm{H} 2$ we analyze the likelihood that individual transactions will fail (failure of individual transactions). Because there is a dearth of reliable and comprehensive data at the deal-level, existing buyout studies have focused either on fund-level analyses, or on limited samples relating to initial public offerings. Our unique data allow us to consider deal-level outcomes across the range of realization options for the buyout market (a common measure of performance in this setting. We focus on a subsample of 4,385 transactions (i.e., acquired companies) completed between 1980 and 2000, giving each deal sufficient time to materialize. We measure their failure as "Failure Score" which is a categorical variable that assumes three values: "-1" if a successful exit (IPO, Secondary LBO, or Trade Sale) has been observed, value of " 0 " for unrealized transactions (censored, living-dead), and "1" for write-off or bankruptcy . Investments made more recently are less likely to have reached the point where exit may occur, leading to rightscensoring, which we take into account. Note, however, that our results are robust to restricting the sample transactions to those made prior to 1993 (to allow the tenth anniversary of a fund), or expanding the data to include all investments done until 2002. 
Explanatory variables our main explanatory variable is the degree of religiosity (REL) in the county where a given buyout-target company is located. We calculate REL as the ratio between the number of religious adherents in the county (as reported by ARDA) and the total population in the county (as reported by the US Census Bureau). Because information on religiosity at the county level is only available for four years (1971, 1980, 1990, and 2000), we follow previous studies and linearly interpolate and extrapolate the data to obtain the values in the missing years. Note, however, that there is very low variance of religiosity across time within a county.

We control for alternative determinants of the likelihood of failure of individual transactions with the following variables: To capture target-specific effects, we use the age of the acquired firm measured at the acquisition date (Target Age); the size of the investment is measured as the natural logarithm of the amount of equity invested in the target company by the (syndicate) buyout fund(s). A syndicated deal is coded 1 , and 0 otherwise. The history of success of the (syndicate) buyout fund(s) is captured by three measures: (1) the (average) success rate (the percentage of successful exits in the entire observation period) of (syndicate) buyout fund(s) participating in the transaction (2) the average historical success rate of buyouts in the focal industry and (3) the average historical success rate of buyouts in the focal state. Other (syndicate) buyout fund(s) characteristics included in our models to proxy for experience and reputational capital of the fund(s) are as follows: the (average) age of buyout fund(s) in the (syndicated) deal at the time of the transaction and the natural logarithm of the (average) capital under management as of 2003. Descriptive statistics for the full set of variables related to the analysis of the likelihood of failure of individual buyouts are reported in Table 1.

We control for alternative determinants of buyout activity with several variables. Our controls attempt to capture the factors influencing the supply of targets: distribution of potential targets across locations, and the familiarity and perception local corporations have regarding buyout activity. First, we consider a proxy for the investment opportunity landscape facing buyouts in a given state and year (the unobserved availability of investment opportunities). We approximate the set of potential targets based on two factors: (1) The number of publicly listed companies that are active in each industry category in the focal year $t$ in state $s$, and (2) the fraction of cumulative buyout activity nationally until year $t$ that occurred in each industry category. We then cross-multiply both vectors to derive the variable "Target Fraction." Second, we control for a possible impact of proximity between the location of private equity firm offices and target-firm headquarters based on the count of the number of private equity firm offices in a given state. This variable is measured as of 2003 because the data is not available over time. We also include the lagged effect (count of deals) of buyout activity in a given state in year $\mathrm{t}-1$ and the age of the buyout industry in a given state, measured as the number of years since the first buyout that occurred in the focal state.

We also control for a collection of county-specific economic and population factors. Population Density is the total county population divided by its area size Economic growth is captured by income growth which is the annual change in per capita income from year $t-1$ to $t$ divided by per capita income in year $\mathrm{t}-1$. Since the county's economy also grows with the number of consumers, economic growth is also measured by population growth which is the annual change in population from year $\mathrm{t}-1$ to $\mathrm{t}$ divided by total population in year $\mathrm{t}-1$. Population is the natural logarithm of the population (Population). College degree is the percentage of adults older than 25 years holding at least one college degree.

\begin{tabular}{|c|c|c|c|}
\hline Variable's & (1) & (2) & (3) \\
\hline Population Density & $0.0045^{\star *}(0.0022)$ & $0.0041^{* *}(0.0021)$ & $0.0038^{*}(0.0019)$ \\
\hline Income Growth & $\begin{array}{l}0.0361^{* * *} \\
(0.0158)\end{array}$ & $\begin{array}{l}0.0374^{* * *} \\
(0.0143)\end{array}$ & $0.0295^{* *}(0.0135)$ \\
\hline Population & $0.0031^{* *}(0.0015)$ & $\begin{array}{l}0.0029^{* *} \\
(0.0014)\end{array}$ & $0.0028^{* *}(0.0014)$ \\
\hline Pop Growth & $0.0137^{*}(0.0070)$ & $0.0105^{*}(0.0071)$ & $0.0098(0.0071)$ \\
\hline College Degree & $0.0082^{*}(0.0043)$ & $0.0063(0.0039)$ & $0.0059(0.0038)$ \\
\hline Unempl Rate & $\begin{array}{c}-0.0268^{* * *} \\
(0.0114)\end{array}$ & $\begin{array}{c}-0.0255^{\star * *} \\
(0.0114)\end{array}$ & $\begin{array}{l}-0.0242^{* *} \\
(0.0113)\end{array}$ \\
\hline Count of Offices & & $\begin{array}{l}0.0914^{* * *} \\
(0.0114)\end{array}$ & $\begin{array}{l}0.0689^{* * *} \\
(0.0130)\end{array}$ \\
\hline Prev BO Activity & & $\begin{array}{l}0.0206^{* * *} \\
(0.0013)\end{array}$ & $\begin{array}{l}0.0218^{* * *} \\
(0.0015)\end{array}$ \\
\hline Target Fraction & & $\begin{array}{l}0.0288^{* *} \\
(0.0135)\end{array}$ & $0.0315^{\star *}(0.0149)$ \\
\hline Age BO Activity & & $\begin{array}{l}0.1253^{* * *} \\
(0.0340)\end{array}$ & $\begin{array}{l}0.1484^{* \star *} \\
(0.0382)\end{array}$ \\
\hline REL & & & $\begin{array}{c}-0.0769^{* * *} \\
(0.0180)\end{array}$ \\
\hline $\begin{array}{c}\text { Census Bureau- } \\
\text { designated areas F.E. }\end{array}$ & No & No & Yes \\
\hline Time F.E. & No & Yes & Yes \\
\hline Industry group F.E. & No & No & Yes \\
\hline \# of observations & 72,216 & 72,216 & 72,216 \\
\hline Log likelihood & -3586 & -2714 & -2659 \\
\hline Prob > chi2 & 0.0000 & 0.0000 & 0.0000 \\
\hline $\begin{array}{l}\text { z value for Vuong test of } \\
\text { ZIP vs. standard Poisson }\end{array}$ & 10.65 & 9.04 & 8.17 \\
\hline
\end{tabular}

Table 1: Local degree of religiosity and buyout activity.

Because the college degree variable is available for 1990 and 2000 only, we derive the control using linear interpolation and extrapolation. Finally, the unemployment rate is the number of unemployed workers in year $t$ divided by the total labor force in year $\mathrm{t}-1$.

Fixed effects our main covariates of interest are measured at the county level, but some key explanatory variables are available only at the state level. We therefore used the Census Bureau-designated areas to absorb all other area-specific characteristics in Figure 1, Appendix B. Note that the Census Bureau definitions are stable over the period of analysis and that areas include states with different political views as well as states that are politically stable and politically variable. Time effects are controlled with year fixed effects in the state activity analysis, and with investment-year fixed effects in the outcome analyses, to absorb the large inter-year variation in activity and returns (e.g., the heyday of a new economic boom may represent transactions that were less driven by potential operating and governance improvements and more driven by the availability of debt capital). Finally, we captured industry group effects with the categories codified by Venture Xpert (based on the 1-digit VEIC classification).

\section{Analysis and Results}

\section{Determinants of the level of buyout activity}

The bivariate correlations show that our measure of buyout activity 
correlates significantly with the number of our theoretical and control variables in Table 2. Furthermore, several of the independent variables are correlated with each other, a situation that calls for the use of multivariate analysis techniques. Note that moderate correlation levels are only between control variables.

Our model assumes that buyout transactions can occur annually, $\mathrm{t}=1983, \ldots 2003$, in all counties in the United States, $\mathrm{c}=1, \ldots$ 3009. The number of buyout transactions in county $c$ (in state $s$ ) for year $t$ is

expressed as:

\section{BO_Activityc, $t=$}

$\alpha R E L_{c, t-1}+\vec{\beta}$ County $_{c,-1}+\vec{\delta}$ State $_{s,-1}+$ CensusBureauAreaF.E. + YearF.E. IndustryF.E. $+\varepsilon_{s,}$

Where our focal covariate, REL, is the degree of religiosity in the county where the firm is located. The vector of county controls includes: "Population Density", Income Growth", "Population", Pop Growth", "College Degree", and "Unempl Rate". State-level controls are additional determinants of buyout activity at the state level: "Target Fraction", "Count Of Offices", "Prev BO Activity", and "Age BO Activity." Including the lagged count of local buyout activity ("Prev BO Activity") to predict current local activity helps to account for the possibility that our empirical models suffer from specification problems due to unobserved heterogeneity. It is important to recognize that many of the observations are censored. Although there are annual transactions in many counties (the uncensored observations), there are no transactions in most other county-year dyads (the censored observations). The large number of zeroes requires nonlinear estimation. Because we have a large sample, and because annual-county transactions vary widely, we estimate equation (1), using a zero-inflated Poisson (ZIP) model (and zero-inflated negative binomial as robustness). While buyout funds are concentrated in four metropolitan areas we observe transactions in many counties over the years indicating that search and coordination costs are not driving our results. We present our results in Table 1. All standard errors are robust and are adjusted for clustering of the observations by private equity firm. Model 1 includes our county-level control variables. Model 2 adds buyout-state covariates, and Model 3 adds our explanatory variables of interest, "REL" The results of the fully specified model (Model 3) include Census Bureau-designated areas, time, and industry fixed effects, and are used for interpretation.

The coefficient estimates suggest that increasing a county's income growth positively and significantly increases the number of buyout transactions by a factor of 1.03. An increase in local population growth, however, does not have a significant impact. Increasing local educational attainment, captured by "College Degree", has a positive effect on current buyout activity with a factor of 1.006, though only at $(p<0.1)$. Increasing the county's unemployment rate decreases buyout activity by a factor of 0.976 .

The coefficients indicate that adding one more buyout office in a state would increase the number of buyout transactions in counties within that state by a factor of 1.07 relative to the mean level in our sample, while holding all other variables in the model constant (mean activity level 0.084 transactions per county per year; adding one more office results in $0.084 \times 1.07=0.090$ transactions per county per year). Increasing a state's previous activity by one transaction would increase current activity by a factor of 1.022. Increasing the opportunity landscape ("Target Fraction") would increase the current level of activity at the county by a factor of 1.03 , while a state where buyout activity started a year earlier, i.e., where business owners, boards of directors, and other institutions (e.g., financial, labor unions) are more accustomed to buyout activity, would experience an increase by a factor of 1.16 , ceteris paribus.

When we turn our attention to the coefficient of the county's degree of religiosity, the results indicate a negative and significant coefficient at $(-0.0769, \mathrm{p}<0.01)$. We also find a significant economic magnitude: an increase in one standard deviation of "REL" is associated with a 7\% decrease in a mean county's buyout activity. Thus, we find support for Hypothesis 1, that the level of activity of leveraged buyouts will be lower at higher levels of religious adherence in the community.

\section{Determinants of the failure of individual buyouts}

The bivariate correlations show that our measure of the exit success of individual buyouts correlates significantly with a number of our theoretical and control variables in Table 3. We run a number of nested models of ordered probit regressions to explain the likelihood of failure of individual buyout transactions. The likelihood of the failure of transaction i, located in county c (states), at time $t(t=1983$, ... 2000), belonging to industrial sector $j$, managed by fund (syndicate) $\mathrm{f}$ is presented by:

\section{2) Failure of Transaction i, c, t, j, f =}

where the dependent variable is "Failure Score" (or "Failure In 5" for robustness using probit model). Our focal covariate REL is the degree of religiosity in the county where the firm is located. The vector of transaction controls includes: "Target Age", "ln (Total Amt)", and "Club Deal Dummy." The vector of buyout controls includes the attributes of the buyout fund or the average attributes of syndicate members in club deals. Specifically, the characteristics are: "ln (Avg Capital MGT)", "Avg of Firm Age", "Avg of Firm Success", "Avg Ind Success", and "Avg State Success."

The results show that our theoretical model fits our data. The specifications shown in Table 4, columns 1-4, add sequentially targeted characteristics (model 1), fund (syndicate), controls (models 2-3), and rate of religious adherents (model 4), and include industry, vintage year, and Census Bureau area fixed effects. Results of the fully specified model suggest that targets one year older than the sample average have a $2.0 \%$ lower likelihood of realizing an unsuccessful outcome, ceteris paribus. Transactions that are one-standard-deviation larger than the sample average ( $\$ 8.9741$ million) have about a 3.3\% lower likelihood of unsuccessful outcome. Syndicated deals have a 5.8\% lower probability of realizing an unsuccessful outcome. Moving to the fund (syndicate) characteristics, and consistent with the fund-level results regarding performance persistence reported by Kaplan our results indicate that a buyout fund (syndicate) with an overall success rate of one standard deviation (0.1839) above the sample average (0.3136) has about a $61 \%$ lower probability of realizing an unsuccessful outcome. Average (syndicate) age has a positive effect on the likelihood of an unsuccessful outcome, though the result is not significant. Average (syndicate) industry-specific success rate of one standard deviation (0.0746) above the sample average age has a $6 \%$ lower likelihood of an unsuccessful outcome, but the result is only significant at the $10 \%$ level. A fund (syndicate) with a state-specific success rate of one standard deviation (0.0888) above the sample average (0.3256) has about an $11 \%$ lower probability of realizing an unsuccessful outcome, ceteris paribus. The coefficients of average capital under management and the average industry success rate are insignificant.

Moving to our focal covariate of interest, negative and significant coefficient for REL 
Citation: Pe'er AA (2015) he Impact of the Institution of Religion on Organizational Decision Making: The Case of Leveraged Buyouts. J Entrepren Organiz Manag 5: 163. doi:10.4172/2169-026X.1000163

Page 8 of 12

\begin{tabular}{|c|c|c|c|c|c|c|c|c|c|c|c|c|c|c|}
\hline Variable's & Mean & s.d. & Min & Max & 1 & 2 & 3 & 4 & 5 & 6 & 7 & 8 & 9 & 10 \\
\hline Current BO Activity & 0.084 & 1.13 & 0 & 15 & & & & & & & & & & \\
\hline REL & 0.49 & 0.28 & 0.03 & 0.9967 & -0.04 & & & & & & & & & \\
\hline Count Of Offices & 4.04 & 10.11 & 0 & 65 & 0.63 & -0.09 & & & & & & & & \\
\hline PrevBO Activity & 4.88 & 8.4 & 0 & 75 & 0.73 & -0.05 & 0.57 & & & & & & & \\
\hline Target Fraction & 97.61 & 152.8 & 0 & 1339 & 0.65 & 0.22 & 0.63 & 0.52 & & & & & & \\
\hline Age BO Activity & 9.8 & 6.4 & 0 & 23 & 0.19 & 0.16 & 0.13 & 0.25 & 0.38 & & & & & \\
\hline Income Growth & 0.04 & 0.05 & -0.41 & 1 & 0.01 & -0.03 & 0.05 & 0.02 & 0.1 & 0.02 & & & & \\
\hline Pop Growth & 0.01 & 0.02 & -0.28 & 0 & 0.19 & 0.02 & 0.03 & 0.16 & 0.06 & 0.01 & -0.09 & & & \\
\hline College Degree & 15.22 & 7.39 & 3.84 & 60 & 0.27 & -0.05 & 0.04 & 0.25 & 0.03 & 0.05 & 0.01 & 0.17 & & \\
\hline Unempl Rate & 6.06 & 3.21 & 0.9 & 40 & -0.03 & 0.08 & 0 & -0.04 & 0.05 & 0.07 & -0.03 & -0.01 & -0.34 & \\
\hline Population Density & 5.34 & 11.08 & -3.50656 & 11 & 0.16 & -0.07 & 0.18 & 0.12 & 0.08 & 0.1 & 0.06 & -0.04 & 0.08 & -0.06 \\
\hline
\end{tabular}

Table 2: Local degree of religiosity and buyout activity.

\begin{tabular}{|c|c|c|c|c|c|c|c|c|c|c|c|c|c|c|}
\hline Variables & Mean & s.d. & $\min$ & $\max$ & 1 & 2 & 3 & 4 & 5 & 6 & 7 & 8 & 9 & 10 \\
\hline Failure Score & 0.7273 & 0.4926 & -1 & 1 & & & & & & & & & & \\
\hline Failureln5 & 0.7891 & 0.408 & 0 & 1 & 0.71 & & & & & & & & & \\
\hline Target Age & 13.4619 & 9.5381 & 1 & 71 & 0.04 & 0.039 & & & & & & & & \\
\hline In (Total Amt) & 8.9741 & 1.9751 & 0.69 & 15.29 & 0.03 & 0.026 & 0.178 & & & & & & & \\
\hline Club Deal Dummy & 0.3886 & 0.4875 & 0 & 1 & 0.07 & 0.062 & 0.024 & 0.148 & & & & & & \\
\hline in (Avg Capital MGT) & 7.0987 & 1.6312 & 0.41 & 10.49 & 0.09 & 0.09 & -0.056 & 0.147 & -0.056 & & & & & \\
\hline Avg of Firm Age & 12.7337 & 11.5159 & 0.33 & 131 & 0 & 0.018 & -0.021 & 0.016 & 0.011 & 0.189 & & & & \\
\hline Avg of Firm Success & 0.3136 & 0.1839 & 0 & 1 & 0.45 & 0.431 & -0.104 & -0.093 & 0.067 & 0.201 & 0.083 & & & \\
\hline Avg Ind Success & 0.325 & 0.0746 & 0.27 & 0.8 & 0.15 & 0.164 & -0.104 & -0.068 & 0.088 & 0.08 & 0.037 & 0.167 & & \\
\hline Ave State Success & 0.3256 & 0.0888 & 0 & 0.9 & 0.14 & 0.117 & 0.002 & -0.024 & 0.036 & 0.045 & 0.123 & 0.093 & 0.084 & \\
\hline REL & 0.49 & 0.28 & 0.03 & 0.9967 & 0.05 & 0.061 & 0.196 & -0.034 & 0.021 & 0.063 & 0.182 & 0.056 & 0.035 & 0.164 \\
\hline
\end{tabular}

Table 3: Descriptive statistics for the determinants of the failure of individual transactions.

\begin{tabular}{|c|c|c|c|c|c|c|}
\hline \multirow[b]{2}{*}{ Variables } & \multicolumn{6}{|c|}{ Dependent Variables } \\
\hline & Failure Score & Failure Score & Failure Score & Failure Score & Failure Score & Failure Score \\
\hline $\begin{array}{l}\text { TargetAge In(Total__ } \\
\text { Amt) }\end{array}$ & $-0.0188^{* * *}(0.0060)$ & $-0.0231^{* * *}(0.0124)$ & $-0.0195^{\star * *}(0.0091)$ & $-0.0205^{\star * *}(0.0097)$ & $-0.0205^{\star * *}(0.0096)$ & $-0.0206^{\star * *}(0.0097)$ \\
\hline ClubDealDummy & $-0.0159^{* \star *}(0.0068)$ & $-0.0179^{* *}(0.0101)$ & $-0.0186^{* * *}(0.0077)$ & $-0.0172^{* * *}(0.0070)$ & $-0.0173^{\star * *}(0.0071)$ & $-0.0173^{* * *}(0.0070)$ \\
\hline In(AvgCapitalMGT) & & $-0.1227^{* * *}(0.0538)$ & $-0.0731^{* * *}(0.0326)$ & $-0.0605^{\star *}(0.0287)$ & $-0.0609^{* *}(0.0287)$ & $-0.0607^{* *}(0.0285)$ \\
\hline AvgOfFirmAge & & $-0.0291^{* *}(0.0134)$ & $0.0079(0.0087)$ & $-0.0158(0.0175)$ & $-0.0151(0.0174)$ & $-0.0152(0.0175)$ \\
\hline AvgOfFirmSuccess & & $0.0002^{*}(0.0001)$ & $0.0002(0.0002)$ & $0.0001(0.0002)$ & $0.0002(0.0002)$ & $0.0002(0.0002$ \\
\hline AvglndSuccess & & & $-2.6549^{* * *}(0.8510)$ & $-2.6583^{* * *}(0.8408)$ & $-2.6580^{* * *}(0.8409)$ & $-2.5944^{* * *}(0.8342)$ \\
\hline AveStateSuccess & & & $-1.2639^{* * *}(0.4452)$ & $-1.2604^{\star * *}(0.4438)$ & $-1.2607^{* * *}(0.4438)$ & $-1.0083^{* * *}(0.3601)$ \\
\hline REL & & & $-1.2639^{* * *}(0.4452)$ & $1.2604^{* * *}(0.4438)$ & $-1.2607^{* * *}(0.4438)$ & $-1.0083^{* * *}(0.3601)$ \\
\hline $\begin{array}{l}\text { AvgOfFirmAge } x \\
\text { REL }\end{array}$ & & & & $-0.7245^{\star \star}(0.3234)$ & $-0.7408^{\star *}(0.3321)$ & $-0.8113^{* * *}(0.3309)$ \\
\hline $\begin{array}{l}\text { AvgOfFirmSuccess } \\
\text { x REL }\end{array}$ & & & & & -0.00000028 & $-0.4052^{* *}(0.1754)$ \\
\hline $\begin{array}{l}\text { AvglndSuccess } x \\
\text { REL }\end{array}$ & & & & & & $-0.1673^{* *}(0.0735)$ \\
\hline $\begin{array}{l}\text { AveStateSuccess } \\
\times \text { REL }\end{array}$ & & & & & & $-0.1003^{* *}(0.0446)$ \\
\hline Industry F.E. & no & yes & no & yes & yes & yes \\
\hline $\begin{array}{l}\text { Investment Vintage } \\
\text { F.E. }\end{array}$ & no & no & yes & yes & yes & yes \\
\hline
\end{tabular}




\begin{tabular}{|c|c|c|c|c|c|c|}
\hline $\begin{array}{l}\text { Census Bureau- } \\
\text { designated areas } \\
\text { F.E. }\end{array}$ & no & no & & yes & yes & yes \\
\hline \# of observations & 4385 & 4385 & 4385 & 4385 & 4385 & 4385 \\
\hline Log likelihood & -4804 & -3972 & -3840 & -3715 & -3704 & -3623 \\
\hline Prob $>(\text { Chi })^{\wedge} 2$ & 0 & 0 & 0 & 0 & 0 & 0 \\
\hline
\end{tabular}

${ }^{*},{ }^{* *},{ }^{* * *}$ statistically distinct from 0 at the $10,5,1 \%$ level , respectively

\section{Table 4: The determinants of the failure of individual transactions.}

$(-0.7245, \mathrm{p}<0.05)$ indicates that the likelihood of a successful outcome is positively associated with the level of religious adherents in a county. The economic magnitude is also significant. An increase of one standard deviation of REL is associated with an $8.3 \%$ reduction in the probability of realizing an unsuccessful outcome.

To further investigate this result, we add in columns 5 and 6 the interaction terms between REL and "Avg of Firm Age", "Avg of Firm Success", "Avg Ind Success", and "Avg State Success." Thus, the model is specified as

3) E [Failure Score Fund attributes, REL, Controls] $=\Phi\left(\beta \rightarrow{ }_{1}\right.$ Fund attributes $+\beta_{2} \operatorname{REL}+\beta \rightarrow{ }_{12}$ Fund attributes ${ }^{\star} \mathrm{REL}+\gamma \rightarrow$ Controls)

Where $\Phi$ is the standard normal cumulative distribution, and all covariates are continuous. The interaction effect is the cross derivative of the expected value of the failure score. To ensure that multicollinearity does not cause imprecise parameter estimates, we follow Kementa's recommendation and conduct a variance inflation factor (VIF) test, adding one interaction term at a time and checking for changes in the coefficients and standard errors. No significant variance in the estimates of the coefficients emerges and the VIF test is 2.54 for the fully specified model. However, conservatively, due to the multiple occurrences of the main effects, we rely on the partial models for interpretation. Our theory suggests that corporations in more religious communities are more likely to pursue an LBO strategy when they are particularly confident about their acceptance by stakeholders in the community and chances of success. In support of Hypothesis 2, we find negative (i.e., failure reducing) signs on interaction terms indicating that fund (syndication) general investment experience (i.e., age), and track record of success (i.e., general success, industry, and location specific) have higher impact on reducing transaction rate of failure for targets headquartered in counties with higher degree of religious adherent.

\section{Robustness and limitations}

Despite the inclusion of controls for demographic and fund variables, one might still be concerned that omitted variable problem drives our results if local religiosity is correlated with some unobserved local demographical or institutional attributes that influence buyout activity and performance. To address this concern, we conducted several robustness checks. First, some factors often correlate with religiosity in the US such as local industrial structure and political conservatism. We included measures regarding unionization of labor (using annual states and industries unionization rates) and political county level presidential and gubernatorial election results. Second, we analyzed separately states with high or low industry union membership, and red and blue states. We find that the effect of religiosity is separated from dominant local political view or degree of unionization. Third, we included buyout fund fixed effects in the regressions. Fourth, we reran out models replacing the census-bureau fixed effects with county level ones. Fifth, we included financial center dummy variable that equals one for targets headquartered in Boston, Chicago, Los Angeles, New York, Philadelphia, San Francisco or Delaware, and zero otherwise. Sixth, we excluded possible outliers such as the counties with the top five percent and the lowest five percent level of buyout activity over the sample period. Lastly, we aggregated the data and average our dependent variable to the state level. Results are very similar to the reported ones suggesting that they are robust to those controls and specifications.

In unreported analyses, we have included the changes in the levels of religiosity in a given country between survey years. We note that this covariate assumed low mean value and standard deviation indicating the stickiness of religiosity in the environment. Including this covariate in our model specifications predicting the level of buyout activity and the determinants of failure in a county have led to insignificant coefficients while maintaining our results regarding the level of local religiosity. These results emphasize that the degree of religiosity in a local is relatively stable and anchored in the norms and values of the community.

Considering the uneven distribution of potential buyout targets across counties we used two alternatives measures of buyout activity. First, we normalized buyout activity at the county-year by potential buyout targets (Target Fraction). Second, we used measured buyout activity at the county-year-sector level using the logistic regression proposed by Papke and Wooldridge. Results are very similar to the reported ones.

We have developed theoretical links between the institutional environment and organizational strategic decision making. The arguments presented by intuitional theory allow us to assume that the observed outcomes of corporate decisions are influenced by the level of religiosity in the environment. We expect that currently unavailable, more granular data (i.e., ideology of top executives and shareholders) will further support our prediction. Along the same lines, while the location of buyout funds is highly concentrated in few metropolitan areas characterized by low level of religiosity, one may research how ideology of buyout executives influences their decisions. Thus, future studies with access to these disaggregated data may explore whether the individual decision-maker level of religiosity positively moderates our proposed link, and possible impacts of bilateral relation in religiosity or affinity across different parties.

While we have used the most comprehensive longitudinal datasets we are aware of regarding buyout activity there are several covariates that we could not operationalize that may strengthen the robustness of our results. For example, the amount invested by management, whether or not the firm is a corporate divestment, the leverage of the firm, is the take-over hostile, and whether or not the transaction is a management buy-out or buy-in. Similarly, while the American religious population is overwhelmingly Christian, other religions (including Judaism, Buddhism, Islam, and Hinduism) which collectively make up about $4 \%$ of the adult population may be clustered in certain counties. Future studies with access to longitudinal data on religiosity including other religions may investigate if our results hold.

\section{Summary and Conclusion}

Religion is a central institution and an important determinant 
of firm conduct and performance. However, our understanding of how religion influences firm behavior and performance is lacking, particularly in the context of corporate development strategies and decision making. In fact, although religion was recognized as one of the five core institutions in the seminal work, it has received very little attention by organizational scholars often. This study is an attempt to bridge this gap by considering the role religiosity plays on organizations' decision-making. We argue that local religiosity influences corporate values and preferences in terms of risk and the social outcomes being considered, as well as what is considered appropriate and expected from the organization in a specific context.

We focus on LBOs, which are particularly suitable example of a major change in corporate strategy to examine our theory. LBOs are fundamentally a risky endeavor for the organization, for its survival, as well as for its stakeholders (e.g., employees, suppliers, and partners). Employing an institutional theory perspective and drawing on the literature on organizational decision making and religion, we suggest that religiosity influences organizations' choice by impacting their preferences and expectations in terms of organizational and social risks, and the outcomes being considered. Organizations in more religious counties are likely to be more risk averse, act less opportunistically, and instead associate higher weights to the effects of their decisions on the local community and stakeholders. Religiosity also impact what they perceive as appropriate in a specific context. In more religious environments intra-group commitment and trust with stakeholders are important considerations for organizations in their pursuit of legitimacy. Therefore, in those environments organizations are more likely to act consistently with what is being expected from them as important actors. Thus, we argue that being embedded in a more religious institutional environment, target firms are less likely to consider collaboration with buyouts since their value creation strategies conflicts with their risk preferences and social roles. Consistent with that, we postulate that in a more religious environment organizations would apply higher success thresholds when initiating or agreeing to a buyout transaction resulting in lower transaction costs and lower failure rate.

Our findings suggest that local levels of religiosity have a statistically significant and economically meaningful impact on the volume and failure rate of buyouts. Specifically, we find a lower likelihood of buyout transactions, and a lower percentage of unsuccessful outcomes for companies headquartered in counties with high levels of religiosity. Corroborating this finding, we found supportive evidence that when applying their screening, firms headquartered in more religious environments attribute a greater weight to socially-contingent (e.g., CSR) and risk-reducing indicators, such as buyout age and track record of success, than firms headquartered in less religious communities.

Infusion of local religiosity into corporate culture may lead to high resistant to change and thus influence firm behavior and outcomes by impacting the organization's objectives and expectations, as well those held by stakeholders. These may not always be in the best interest of the shareholders, implying that some potentially value creating transactions are blocked by organizational decision making. While in the more frequently studied case of mergers and acquisitions managers often derive private benefits at the expense of shareholders by pushing for non-value generating transactions, it seems that in the case of buyouts, managers may block value-generating transactions at the detriment of shareholders' wealth. Interestingly in our context, the benefits that managers derive are intrinsic, rather than extrinsic nature, which supports recent extensions of agency theory to non-financial drivers of behavior.
The observed impact of within-country variation in religiosity complements existing work in the area of institutional theory, which has largely studied cross-country phenomena. While existing literature assumes that the underlying forces are operate at the national level we show that instuitional logic is operating and influencing decision making at a much more granular level. Thus, we provide important evidence for the relevance of this construct in an otherwise more homogeneous within-country setting. Our findings also have important implications for practitioners, as they point to the role of religiosity as an observable proxy for factors that determine a firm's culture, risk appetite, and performance outcomes. Accordingly, buyout investors, lending banks and even debt rating agencies should consider taking a closer look at this currently overlooked variable, as it may enable them to take more accurate investment decisions. In a sense, a high level of religiosity in the institutional context of an acquisition or buyout target can be seen as a safety net against (excessive) risk taking. Possibly the use of location-specific risk heuristics that capture within country variation in the level of religious adherence can lead to a better assessment of the inherent risk attributes of a given investment proposal. The level of religious adherence seems to serve a similar function as interpersonal trust in business transactions, but unlike the latter, the level of religious adherence is an easily observable and measureable proxy.

We see this study as a first step towards a deeper understanding of the ways in which the institutional context moderates the performance consequences of alternative corporate development strategies. Given our findings, additional research using finer-grained measures of the institutional context seems well warranted. Accordingly, our results point to a number of avenues for future theoretical and empirical research. Promising areas of analysis include the impact of the institutional context on other corporate development strategies, such as growth-oriented or technology-grafting acquisitions or strategic alliances. Similarly, a more detailed assessment of the exact mechanisms through which the local context influences firm conduct and performance is also likely to lead to interesting findings that would complement the present study. Finally, additional research on the role of changes in the institutional context on firm conduct and performance seems warranted, possibly based on a longitudinal research design in Table 1.

Current BO Activity is a count of all buyouts made in a given calendar year of companies located in a given county. REL is the ratio of the number of religious adherents in the county to the total population of the county. Count of Office is the number of PE firm offices at states as of 2003; Prev BO Activity is the aggregated level of buyout activity at states at time t- 1 . Target Fraction, which is defined as the number of publically listed companies at states, at time $t$, belonging to industry $\mathrm{i}(\mathrm{i}=1, \ldots 10)$ times the fraction of countrywide completed buyout transactions between 1980 and t belonging to industry i. Age BO Activity is the number of years since the first buyout transaction occurred at state $s$ and time $t$. Income Growth at the county is the annual change in per capita income from year $\mathrm{t}-1$ to $\mathrm{t}$ divided by per capita income in year $t-1$. Pop Growth is the annual change in population from year $\mathrm{t}-1$ to $\mathrm{t}$ divided by total population in year $\mathrm{t}-1$. College Degree is the county's percentage of adults older than 25 years of age holding at least a college degree. Unempl Rate is the number of unemployed workers in the county in year $t$ divided by the total labor force in year $t$. Population Density is the total county population divided by its area size in year $t$.

The Table 2 presents in the coefficient estimates from a zeroinflated poison specification. The dependent variable is the level of buyout activity (aggregate number of transactions) at county $c(c=1, \ldots$ 
3009) in states, at time $\mathrm{t}(\mathrm{t}=1980, \ldots 2003)$. The specification includes our focal explanatory variable REL defined as the ratio of the number of religious adherents in the county to the total population of the county. Population Density is the total county population divided by its area size in year t. Income Growth at the county is the annual change in per capita income from year $t-1$ to $t$ divided by per capita income in year $\mathrm{t}-1$. Population is the natural logarithm of the population. Pop Growth is the annual change in population from year $t-1$ to $t$ divided by total population in year t-1. College Degree is the county's percentage of adults older than 25 years of age holding at least a college degree. Unempl Rate is the number of unemployed workers in the county in year $t$ divided by the total labor force in year $t$. Count of Office is the number of PE firm offices at states as of 2003; Prev BO Activity is the aggregated level of buyout activity at states at time $\mathrm{t}-1$. Target Fraction, which is defined as the number of publically listed companies at states, at time $t$, belonging to industry $i(i=1, \ldots 10)$ times the fraction of countrywide completed buyout transactions between 1980 and $t$ belonging to industry i. Age_BO_Activity is the number of years since the first buyout transaction occurred at state $s$ and time $t$. Year, industry, and Census Bureau designated area fixed effects are included in some of the specifications. Standard errors are in parentheses in Table 3.

Failure Score is a categorical variable that assumes three values: “- 1 " if a successful exit (IPO, Secondary LBO or Trade Sale) has been, value of " 0 " for unrealized transactions (censored, living-dead), and " 1 " for write-off or bankruptcy. FailureIn5 takes a value of "0" for successful exit (defined as above) and a value of " 1 " otherwise; Club Deal Dummy is coded " 1 " for syndicate (club) deals and "0" otherwise. Target Age is the age of the acquired firm measured at the acquisition date. Ln (Total_Amt) is the natural logarithm of the amount of equity (intsd US\$) invested in the target company by the (syndicate) buyout fund(s). Avg of Firm Success is the (average) success rate of (syndicate) buyout fund(s) participating in the transaction. Avg Ind Success is the average historic success rate of buyouts in the focal industry. Avg State Success is the average historic success rate of buyouts in the focal state. Avg of Firm Age is defined as the (average) age of buyout fund(s) in the (syndicated) deal at the time of the transaction. In (Avf Capital MGT) is the natural logarithm of the (average) capital under management by the buyout fund(s) as of 2003. REL is the ratio of the number of religious adherents in the county to the total population of the county.

The Table 4 presents in the results of ordered probit model specifications. The dependent variable is "Failure Score" is a categorical variable that assumes three values - "- 1 " if a successful exit (IPO, Secondary LBO, or Trade Sale) has been observed; value of "0" for unrealized transactions (censored, living-dead); and "1" for write-off or bankruptcy. Explanatory variables are: Club Deal Dummy is coded " 1 " for syndicate (club) deals and "0" otherwise. Target Age is the age of the acquired firm measured at the acquisition date. Ln (Total_Amt) is the natural logarithm of the amount of equity (in tsd US \$) invested in the target company by the (syndicate) buyout fund(s). Avg of Firm Success is the (average) success rate of (syndicate) buyout fund(s) participating in the transaction. Avg Ind Success is the average historic success rate of buyouts in the focal industry. Avg State Success is the average historic success rate of buyouts in the focal state. Avg of Firm Age is defined as the (average) age of buyout fund(s) in the (syndicated) deal at the time of the transaction. Ln (Avf Capital MGT) is the natural logarithm of the (average) capital under management by the buyout fund(s) as of 2003. "REL" is the ratio of the number of religious adherents in the county to the total population of the county. Investment vintage, industry, and Census Bureau designated area fixed effects are included in some of the specifications. Standard errors are in parentheses.

\section{References}

1. Scott WR (1995) Institutions and Organizations (Foundations for Organizational Science).

2. Chan CM, Isobe T, Makino S (2008) Which country matters? Institutional development and foreign affiliate performance. Strategic Management Journal 29: 1179-1205.

3. Meyer KE, Estrin S, Bhaumik SK, Peng MW (2009) Institutions, resources, and entry strategies in emerging economies. Strategic Management Journal 30: 61-80.

4. Henisz WJ (2000) The institutional environment for multinational investment. Journal of Law, Economics and Organization 16: 334-364.

5. Kostova T, Zaheer S (1999) Organizational legitimacy under conditions of complexity: The case of the multinational enterprise. Academy of Management Review 24: 64-81.

6. Miller SR, Eden L (2006) Local density and foreign subsidiary performance. Academy of Management Journal 49: 341-355.

7. Rosenzweig PM, Singh JV (1991) Organizational environments and the multinational enterprise. Academy of Management Review 16: 340-361.

8. Goshal S, Young C (1993) Organization Theory and the Multinational Corporation pp: 53-76.

9. Zaheer S (1995) Overcoming the liability of foreignness. Academy of Management Journal 38: 341-363.

10. Delmas MA, Toffel MW (2008) Organizational responses to environmental demands: opening the black box. Strategic Management Journal 29: 10271055.

11. Darnall N, Edwards D (2006) Predicting the cost of environmental management system adoption: the role of capabilities, resources and ownership structure. Strategic Management Journal 27: 301-320.

12. Bansal P (2005) Evolving sustainably: A longitudinal study of corporate sustainable development. Strategic Management Journal 26: 197-218.

13. Papadakis VM, Lioukas S (1998) Strategic decision-making processes: The role of management and context. Strategic Management Journal 19: 115-147.

14. Friedland R, Alford RR (1991) Bringing society back in: Symbols, practices, and institutional contradictions. In: Walter W, Powell, Paul J, DiMaggio, (eds.), The New Institutionalism in Organizational Analysis, Chicago: University of Chicago Press.

15. Thornton PH (2004) Markets from culture: Institutional logics and organizational decisions in higher education publishing. Stanford University Press pp: 232263.

16. Chan-Serafin S, Brief AP, George JM (2012) How does religion matter and why? Religion and the organizational sciences. Organization Science 24: 15851600

17. Smith A (1776) An inquiry into the Nature and Causes of the Wealth of Nations

18. Weber M (1930) The Protestant ethic and the spirit of capitalism. Allen and Unwin.

19. Iannnaccone LR (1998) Introduction to the economics of religion. Journal of Economic Literature 36: 1465-1496.

20. Barro RJ, McCleary RM (2003) Religion and economic growth. Working paper, Harvard Business School, Boston.

21. Haveman HA, Rao H (1997) Structuring a theory of moral sentiments: institutional and organizational coevolution in the early thrift industry. American Journal of Sociology 102: 1606-1651.

22. Thornton PH, Ocasio W (2008) Institutional logics. The Sage handbook of organizational institutionalism.

23. Scott WR, Reuf M, Mendel PJ, Caronna C (2000) Institutional Change and Health Care Organizations from Professional Dominance to managed Care. University of Chicago Press, Chicago.

24. Boltanski L, Thevenot L (2006) On Justification: Economies of Worth. Princeton Studies in Cultural Sociology, Princeton University Press.

25. Gellman L (2013) Investing as a Religious Practice. Wall Street Journal. 
Citation: Pe'er AA (2015) he Impact of the Institution of Religion on Organizational Decision Making: The Case of Leveraged Buyouts. J Entrepren Organiz Manag 5: 163. doi:10.4172/2169-026X.1000163

26. Lerner J, Hardyman GF, Leamon A (2004) Venture capital and private equity: An instructor's manual (3rd edn.), John Wiley and Sons, New York.

27. Stromberg $P$ (2007) The new demography of private equity. Working paper Swedish Institute for Financial Research, Stockholm School of Economics.

28. Ljungqvist A, Richardson M (2003) The investment behavior of private equity fund managers. Working Paper, New York University Stern School of Business, New York.

29. Peer A, Gottschalg O (2011) Red and blue: the relationship between the institutional context and the performance of leveraged buyout investments. Strategic Management Journal 32: 1356-1367.

30. Hoskisson RE, Eden L, Lau CM, Wright M (2000) Strategy in emerging economies. Academy of Management Journal 43: 249-267.

31. Meyer KE, Peng MW (2005) Probing theoretically into Central and Eastern Europe: transactions, resources, and institutions. Journal of International Business Studies 36: 600-621.

32. Tsui A (2004) Contributing to global management knowledge: A case for high quality indigenous research. Asia Pacific Journal of Management 21: 491-513.

33. La Porta R, Lopez-de-Silanes F, Shleifer A, Vishny R (1997) Legal determinants of external finance. Journal of Finance 52: 1131-1150.

34. Yuchtman-Yaar Y, Alkalay Y (2007) Religious zones, economic development and modern value orientations: Individual versus contextual effects. Social Science Research 36: 789-807.

35. Gompers P, Lerner J (2002) The venture capital cycle. MA: MIT Press, Cambridge.

36. Boddewyn JJ, Brewer TL (1994) International business political behavior: new theoretical directions. Academy of Management Journal 19: 119-143.

37. Klasa SW, Maxwell F, Ortiz-Molina H (2008) The strategic use of corporate cash holdings in collective bargaining with labor unions. Working paper, University of British Columbia, Vancouver, BC.

38. King A, Lenox M (2000) Industry self-regulation without sanctions: The chemical industry's 'responsible care' program. Academy of Management Journal 43 698-716.

39. Hofstede GH (1980) Culture's consequences: International differences in workrelated values. Beverly Hill, CA: Sage Publications.

40. Porter ME (2000) Attitudes, values, beliefs, and the microeconomics of prosperity. In Harrison LE and Huntington SP (edn.), How Values Shape Human Progress pp: 14-28.

41. DiMaggio PJ (1994) Culture and economy. In Smelser $N$ and Swedberg $R$ (Edn.), The Handbook of Economic Sociology pp: 27-57.

42. Khanna T, Rivkin JW (2001) Estimating the performance effects of business groups in emerging markets. Strategic Management Journal 22: 45-74.

43. DiMaggio PJ, Powell W (1983) The iron cage revisited: Institutional isomorphism and collective rationality in organizational fields. American Sociological Review 48: $147-160$

44. Powell (1988) Institutional effects on organizational structure and performance In: Zucker LG (ed.), Institutional Patterns and Organizations: Culture and Environment pp: 115-36.

45. Tolbert PS, Zucker LG (1996) The institutionalization of institutional theory. In Handbook of Organization Studies pp: 175-190.

46. Rao H, Monin P, Durand R (2003) Institutional change in toque ville: Nouvelle cuisine as an identity movement in French fastronomy. American journal of sociology 108: 795-843.

47. Thornton $\mathrm{PH}$, Ocasio W (1999) Institutional logics and the historical contingency of power in organizations: Executive succession in the higher education publishing industry, 1958-1990. American Journal of Sociology 105: 801-843.

48. Lounsbury M (2002) Institutional transformation and status mobility: The professionalization of the field of finance. Academy of Management Journal 45: $255-266$.

49. Stulz R, Williamson R (2003) Culture, openness, and finance. Journal of Financial Economics 70: 313-349.

50. Gelman A (2008) Red State, Blue State, Rich State, Poor State: Why Americans Vote the Way They Do. Princeton University Press

51. Osoba B (2003) Risk preferences and the practice of religion: evidence from panel data. Un published Working Paper, West Virginia University.

52. Halek M, Eisenhauer JG (2001) Demography of risk aversion. The Journal of Risk and Insurance 68: 1-24.

53. Dehejia R, DeLeire T, Luttner EFP (2007) Insuring consumption and happiness through religious organizations. Journal of Public Economics 9: 259-279.

54. Hoorn A, Maseland R (2013) Does a Protestant work ethic exist? Evidence from the well-being effect of unemployment. Journal of Economic Behavior and Organization 91: 1-12.

55. Coval JD, Moskowoitz TJ (1999) Home bias at home: Local equity preference in domestic portfolios. Journal of Finance 6: 2045-2073.

56. Coval JD, Moskowitz TJ (2001) The Geography of Investment: Informed Trading and Asset Prices. Journal Political Econ 109: 811-841.

57. Murphy KM, Shleifer A (2004) Persuasion in politics. American Economic Review 94: 435-439.

58. Hilary G, Hui K (2009) Does religion matter in corporate decision making in America. Journal of Financial Economics 93: 455-473.

59. March JM, Olsen JO (2006) The Logic of appropriateness. In M. Moran, M Rein, and R.E. Goodin (edn.), The Oxford Handbook of Public Policy, Oxford University Press pp: 689-708.

60. Muscarella CJ, Vetsuypens MR (1990) Efficiency and organizational structure: A study of reverse LBOs. Journal of Finance 45: 1389-1413. 